that aqueous solutions extracted from light benzene reduce ammoniacal silver solutions, the author concludes that aldehydes are contained in the first of fraction $L 1$ with sodiut trisulphite, but obtained unable to examine the mixture of aldehydes and ketones more closely. He, however, detected the premation of iodoform and the indigo reaction with orthoditrobenzaldehyde and sodium hydroxide. A cording to Michael, a bright resinous substance is
obtained on boiling aldehyde with an alcoholic solution of resorcinol a.jd a minute quantity of hydrochloic acid (see this Journal, 1884, 253). The author has tion to light benzene. isolate this product from any of the fractions obtained by the distillation of light benzene. He, however, obtained a faint reaction of ethyl alcohol from a samnight, and concludes from this result, that light ben. decomposed by water with formation of is gradually 5. Phenols. ducted in the following manner: After treatiment with hydrochloric acid the light benzene was shaken up with dilute soda lye. The alkaline extract wa steam or extracted with ether. In both cases a prodity was too small to admit of further investigation.

6. Mercaptans. - To detect the presence of these col pounds in light benzene the different fractions were ond series of trials they were added to an alcoholic solution of mercuric chloride. The presence of mer-
captans could not, however, be established with certainty. as only a slight turbidity was obtained.
7. Detection of Bodies belonging to the Pyrol, Thio7. Detection of Bodies belonging to the Pyrol, Thio-
phen and Furfuran Series, also of Hydrocarbons of the greenish color - The vapor from fraction $L 1$ imparts drochloric ẫ. The reaction with the phenanthrquinone and with isatin and concentrated sulphuric certainty that no closed chain compounds of the pyrol, urfuran, or thiophen series are present. It is not poswith a concentrated solution of picric acid, although benzene was found in the residue obtained by fractional distillation.

8. Unsaturated Compounds. - The different fractions nine very eagerly, and form additive as well as substitution compounds. The group of unsaturated compounds includes derivatives of acetylene, the author cuprous chloride to light benzene and allowing the mixture to stand, a red-brown precipitate is obtaine

THE UNBURNED GASES OF GAS STOVES AND BURNERS."

I HAVk been working for some time with a view of determining whether the gases escaping as flue gases
from gas stoves and different burners were really free from gas capable of combustion, such as carbon mon. quantity of carbon monoxide present. if any, but this problem was beset with so many difficulties that for the moment I abandoned it and contented myself for the present with determining the quantity of unburninight exist. For this purpose I arranged an ap. tilled with strong sulphuric acid, and two weighed U tubes filled with soda lime, through which the flue gases were first passed. These absorbed the water and carbon dioxide contained in the flue gases, leaving and carbon monoxide to pass through a red hot glass tube filled closely for $15 \mathrm{in}$. with oxide of copper, prewere then passed through strong sulphuric acid and and the results were calculated on the gas measured at $60^{\circ} \mathrm{Fahr}$. and thirty in. barometric pressure, from the measure of gas drawn into the aspirator (treated as vapor absorbed in the tubes were then added on to make up the measure of flue gas originally employed coal gas employed was previously passed through large combustion, and at the the carbon dioxide and water vapor present in the air itself by passing it by means of another respirator tubes previonsly weighed. 0.41 to 0.66 grain per cubic foot of air, and the water rom 3.51 to 7.23 grains in the same volume. The the flue gases, after deducting the quantities actually present in the air, were taken as those due to the com-
bustion of the coal gas. 'The standard I employed was bustion of the coal gas. 'The standard I employed was one used by Professor Roberts.Austen in his analysis
of the flue gases from the burning of coal, and the apof the flue gases from the burning of coal, and the apparatus employed was generally similar to that also bon,-actually derived from the combustion of the gas in the stove or burner. The total quantities of carbon dioxide and of water in the tlue gases amounted to from 66 to 10.8 grains per cubic foot for the former
and from 5.6 to $10^{\circ}$ grains of the latter, in the same and froin 5

volume.
The amount of flue gas passed in each experiment was about one cubic foot, and although the variations in showing that the combustion of gas, wh sn burned

* Resd by Mr. William Thomson, F.R.s. Ed., F.C.S., before the
Chemical Section of the British Association. in gas stoves for heating purposes, is much more in- a
complete than one might be led to suppose. The only burner in which the weights of the tubes remained constant after passing the burned gas, and urned to its highest point. In another expas not with the flame turned full on, 12.04 and 3.09 respectvely of carbon and hydrogen escaped combustion per
000 of carbon completely burned. The next nearest approach to complete combustion was in an Argand burner, in which all the carbon was
completely burned, but an amount representing 0.2575 part of hydrogea escaped combustion per 1,000 parts periment 0.113 of carbon and 2.5414 of hydrogen escap. ing combustion were registered per 1,000 parts of carbon completely burned. 'Then came one of Bray's ordinary flat flaine burners, burning four cubic feet per our, which gave 11.12 of carbon and 0.95 hydrog
unburned per 1,000 of carbon completely burned.

Following in order these results came the Welsbac mantel composed of a filmy thickness of the oxides of zirconium and titaniurn, the mantel being surrounded by a glass tube similar to that used in some paraffin oil lamps. In this case the unburned carbon exceeded in amount the un burned hydrogen, there being 15.486 of the former and $3 \cdot 794$.
pletely burned carbon.

Three experiments were made with a Marsh-Green all's heating stove, in which three Bray's luminous
burners were employed. The first was wade with a 126 and 3.0 parts of carbon and hydropen were riggistered per 1,000 parts of carbon completel urned.

The second experiment, with a consumption of 5.74 cubic feet per hour, gave 37.6 and 11.8 respectively of
carbon and hydrogen unburned. The third experi carbon and hydrogen unburned. The third experiment, with an increased consumption of gas (7.1 cubic
feet per hour), gave $97 \cdot 4$ and $12 \cdot 1$ of carbon and hydroeet per hour), gave 97.4 and

Two experiments were made with one of $\mathrm{Mr}$. Thomas Fletcher's heating stoves, in which eight Bunsen burners play upon some fancy metal work (iron coated with
magnetic oxide). The one experinent in which the amount of gas passing was not measured gave 43.3 carbon and 246 of hydrogen unburned per 1,000 of
carbon completely burned. In the second experiment. where 6.81 cubic feet of gas were burned per hour, 66 ed were registered.

One experiment was made with one of Mr. Fletcher's stoves, in which twenty Bunsen burners play on asbestos projecting from a fireclay back, with a con-
sumption of $8 \cdot 14$ cubic feet of gas, 138.9 and 11.7 part respectively of carbon and hydrogen per 1,000 parts of

In a stove in which the hot gases rise to the top of a
cylinder flled with pipes (through which cold air passes to be heated), and from the bottom of which the burned gases escrpe after having cooled to a considerable extent, upward of 200 parts of carbon escap-
ed combustion per 1,000 parts of carbon completely burned.

\section{CORRECTING IRREGULARITIES OF THE} TEETH.*

By V. H. Jackson, M.D., D.D.S., New York, N. Y. Thrare have been presented to the profession by dental specialists from time to time new systems for
correcting irregularities of the teeth. Each has recorrecting irregularities of the teeth. Each has re-
ceived more or less attention, and some of them wil continue to be of service as long as irregularities nee

Orthodontia will no doubt eventually become distinct specialty of dentistry, but it is necessary at present for the general practitioner to be more or less amiliar with the systems in use, in order that he may
hoose that which will be the most effective in a given case and require the least outlay in construction. It is my purpose in this brief paper to describe and denonstrate with models and apparatus some methods of applying removable springs without the use of a plate for regulating teeth, describing wethods that 1 results in a limited time, and in passing I desire to express a growing confidence in the use of the removable
pring for movine teeth. Piano wire is at present the pring for moving teeth. Piano wire is at present the
pest spring for the purpose, although spring gold, iully if the temper is not drawn while soldering, and that can be avoided in some cases by keeping th spring portion cool, or by using soft solder, which is The diffeculty experienced in regulating the teeth of
The the lower arch of ten prompts the dentist to delay the
operation from time to time, and more of ten to avoid even its consideration.

onsiderable length of time spring appliances that are gentlemen present, meta rection of irregularities of the teeth in the lower arch.

Fig. 1. In the model here presented it will be seen

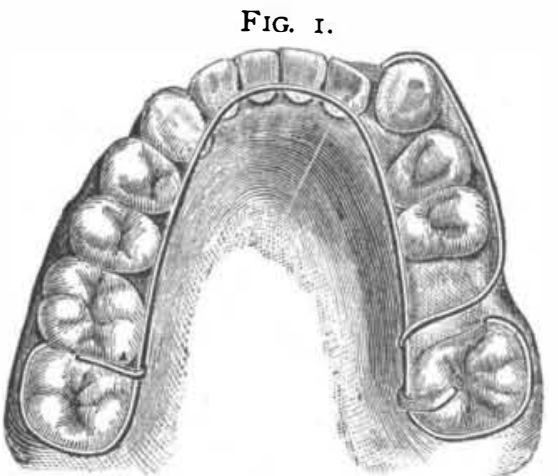

that the right inferior cuspid was much too prominen * Read before the International Medical Congress at Berlin.-Dental and articulated outside of the upper teeth, there being The first space for it in the arch.

and a piano wire was formed to the lin was defective. theth in the arch, following the line of the gum to the distal tooth on either side, around which the end were formed to clasp. The gum was very prominen just back of the molars, and accordingly the plaster
model on which the appliance was formed was the carved slightly to allow the spring to more perfectly A second spring wire was then formed to join the one described, and pass just in front of the secon molar through the space made by the extraction of in a curve on the anterior surface of the prominent cuspid. The two spring wires were then joined with soft
solder, having first wound the part forming the joint with small copper wire. The whole appliance can, if The pressure of the spring was regulated by bending The pressure of the spring was regulated by bending
it toward or from the main wire, and by curving the and bicuspids backward, and move the cuspid into proper line within a month's time.
A variety of nethods have been adopted to keep this form of appliance from pressing on the gum and
slipping off from the teeth. Soms of these have been published. main wire and reaching into the spaces between the similar wire extended on to the grinding surface, usually at the junction of two teeth, to keep the fixture from pressing on the gum. cases. the most rapid in moving the teeth, and of the least inconv.

The inner bar can be stiffened at any place desired by winding with binding wire, and flowing over it tin similar manner at any stage of the operation.

A spring can extend from the main wire to either side of the arch to move teeth out into line, or to the arch to force prominent teeth back ore incisors by pressing them against the main Fig. 2. - The arch can be easily expanded in many
wire

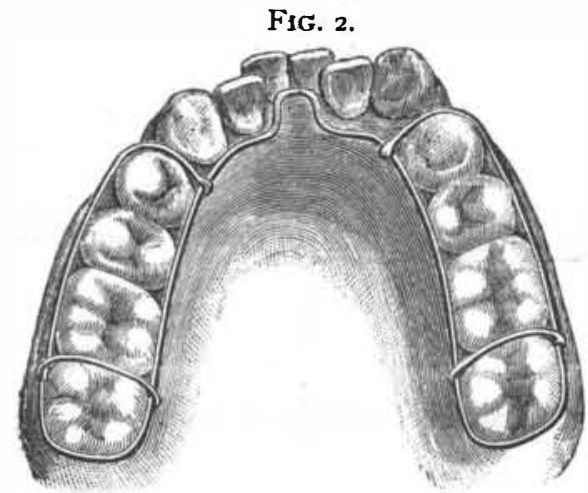

that purpose, the principal or foundation spring can be arranged either on the inside or outside of the arch
as it is found hest suited to the individual case, al though it should in most cases have a small loop form-
ed in the wire at the median line of the arch. This point I referred to in a previous paner in the of spreading the anterior part of the lower arch with plate without covering the teeth. The same wire hould extend back along the line of the necks of the ceth and clasp around the last one in the arch, and bicuspid, and there extend over the grinding surface the appliance from pressing on the gun, and also clasp The opening of the median line loop from time to ine will spread the bicuspid portion of the arch. The into line by the foundation spring, by opening the Foo and shaping the spring to press against them.
loor purpose the spring should not be too stiff. One or more additional loops of wire may pass over
the grinding gurface at the junction of two theth and the grinding surface at the junction of two treth and
be united to those on either side, if the appliance is ot otherwise well retained This device for attaching apparatus to the teeth I which will be given further on. overcrowded lower teeth into proper line (as well as Fig. 3.

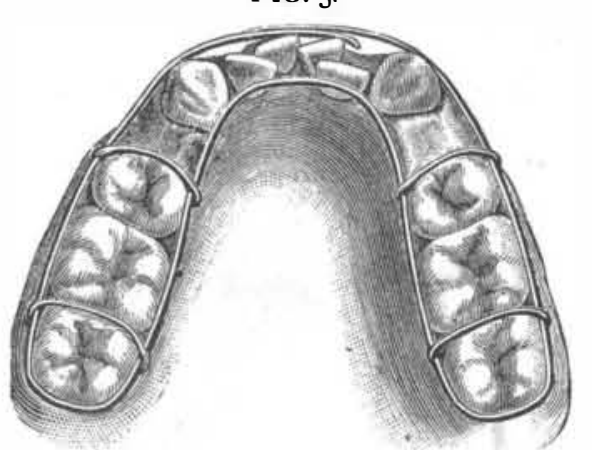

those of the upper arch) where a bicuspid has been renoved on either side, leaving a space, is to arrange a spring wire on the lingual side of the teeth in the line
they should assume when regnlated. The wire should gain forward on the labial side, forming a crib as de scribed, except that the ends should be left free to form 
springs which extend forward on the labial side of the teeth, beyond the median line, thus passing each
other. By the inward pressure of the springs the teeth are forced against the main wire and thus drawn into sure exerted on the teeth embraced between the inner and outer spring wires squeezes the teeth also to the
right and left as if they were being directly pushed right, and left as if they were being directly pushed
backward along the curved inclosure of the crib, which backward along the curved inclosure of the crib, which ments of the teeth in the desireil directions.

If the front teeth are not prominent enough, as seen in Fig. 4, the appliance should be made the same as

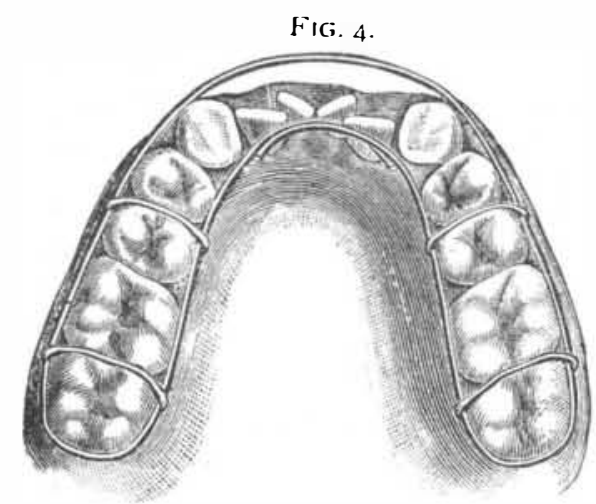

the one last described, except that the main wire should be arranged on the labial side of the teeth and the springs on the lingual side, to press the teeth out
into the circle made by the inain wire in front of Fig. 5.-A "crib" for one side of the arch, with a spring wire passing across to the opposite side, providFIG. 5 .

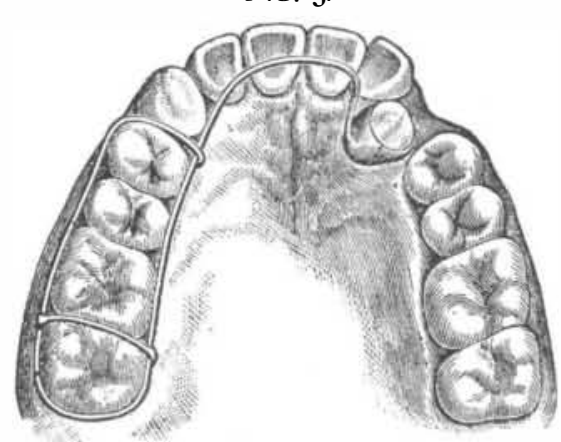

ed with a partial clasp fitted to the tooth to be moved and soldered to the wire end, is efficient in some cases
for pressing into line a cuspid or other tooth that is in-

side of the arch. the arch and the two be joined by a sinall spring wire, to which can be attached a T piece to draw back prosame time spread the anterior part of the arch by having the spring press against the lingual side of the teeth that are to be moved outward.

I now present the model of the teeth of a lady thirty-six years old, all of whose upper front teeth closed inside the lower ones.
It will be seen that one lateral incisor and bicuspid and three molars are missing, some of them having been extracted years ago with the hope of correcting the irregularity. But the teeth had crowded together and the articulation became so changed as to give an unpleasant expression to the features. Besides this, the labial surfaces of the superior incisors were becom ing worn.

The second model was made from an impression raken while the apparatus was in the mouth, and ward.

The difficulty that is often experienced of moving nearly all of the oral teeth in one direction was ver marked in this case, as will be seen by the models A crib was made for each side of the arch, to encircle all of the teeth back of the incisors; a, slight separation was made by wedging in front of the cuspids, and the space on the line of the gum and surrounding the cuspid bicuspids and molars. This was supported and made to more firmly clasp the teeth by making cross bars to connect the two sides of the crib by passing over the articulating surface at the junction of the teeth, serving also to keep the crib from pressing on the gum.

There was a loop soldered to the crib wire opposite the palatal surface of the first molar on each side of the wire formed like the letter $S$, and extended forward passing' just 'jack of and following the curve of the incisor:- Thare were placed on the incisors gold collars with livg soldered on their palatal surfaces, to hold that portivn of the spring in position.

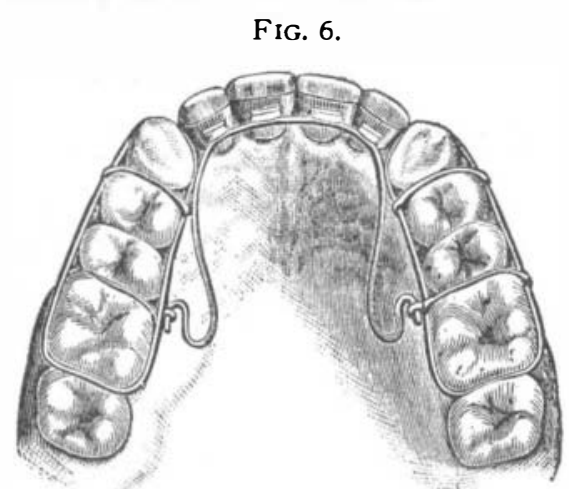

Fig. 6 shows the device in place on the four in Fig. 6 shows the device in place on the four in
in another completed case of the same character. Pressure was made as needed, by straightening th

The incisors were moved rapidly, and when suffeient- the labial surface of the right inferior cuspid when the forward the portion of the crib in front of the teeth were articulated meacured about three-fourth cuspids was removed, and a piece of piano wire was of an inch (Fig. 9).

soldered to the original spring wire, which extended to the distal sides of the cuspids, by the application of as then attached by solder to the original one, as before, to move the bicuspids forward, and at the same me one of the cuspids was prepured to be rotated by placing on it a collar, with a cylinder soldered to its paposite side of the arch and hooked into the toop in the crib.

Fig. 7.- A cuspid or other tooth that is inside and a way at the same time be forced into line by constructing a crib for the back teeth on the same side of the
arch as the teeth to be regulated, and from this crib arch as the teeth to be regulated, and from this crib respective labial and lingual sides of the teeth which are to be moved.

FIG. 7 .

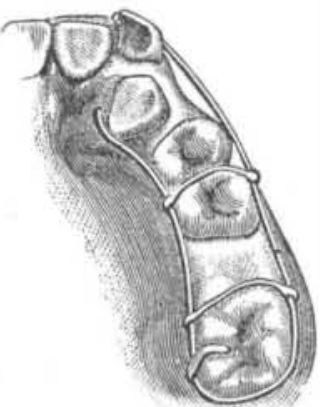

Fic. 8 .

Fig. 8 shows an appliance on a model for rotatiug a lowing the outline of the gum as before described, and the ends left free to act as a spring on the labial and lingual surface of the tooth to be rotated, on which is placed a collar having slight depressions or sockets to receive the ends of the springs, which are curved to proper form to cause pressure in the desired direction ance is easily made, can be used for any tooth, and does rapid work. The wide range of the action of these arius is peculiarly noticeable, for by them every con. ceivable direction may be given to the tooth according as one, or the other, or both of the arms shall be ad justably bent for action.

In uniting piano wires to form the crib, the joints are strengthened by first drawing the temper of the end of the wire, and flattening it very thin with the hamiuer,
again drawing the temper and bending it around the main wire before soldering. If great strength is needed ery thin copper wire should be wound about the joint efore soldering. It is always well to make the parts bright and tin them before uniting, if soft solder is to be used. Use at all times a very weak solution of muriate of zinc, and preferably employ the solderine iron. Collars are indispensable in many cases for holding the Cor the spring in position on the teeth.

For the ordinary case a lug may project from the made, usually by soldering to the collar a loop of small platinuin wire in suitable position to receive the end of the rotating spring.

If the crib is not well retained by the devices previous y described, a separation should be made by wedging, the appliance shown in Fig. 12 was made and adjusted, thect the sides of the crib, or a spring can extend from as seen in Fig. 13

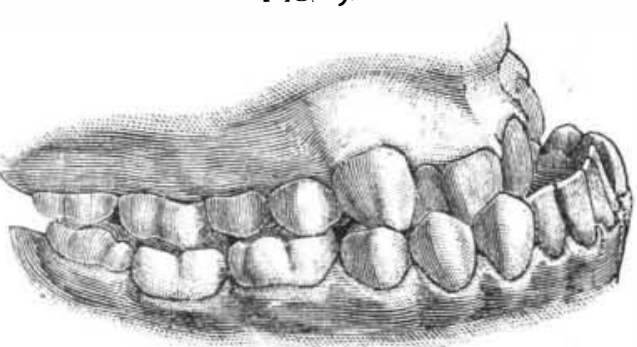

Ti,e superior maxilla was not, however; well developed, and the incisors needed to be made more prominent A split plate (Fig. 10) was made as described by $\mathrm{Dr}$. FiG. 10.

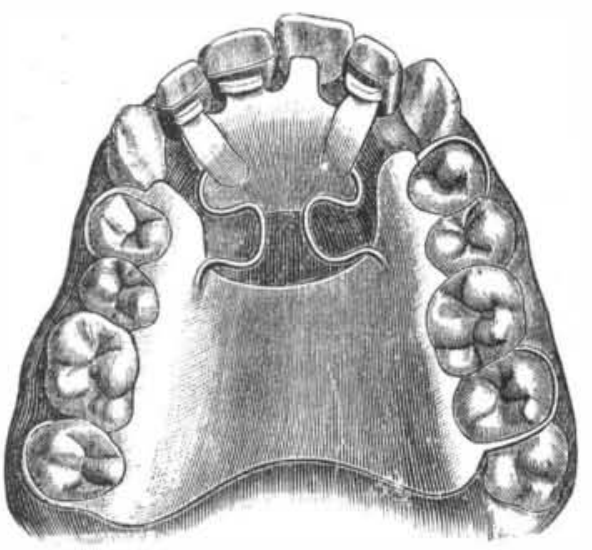

W. H. Coffin. of Eugland, except that it did not cover the teeth or open the bite. It. was strongly retained by two wire clasps extending from either side to clasp leaving the anterior part sufficiently large to cover the interuaxillary portion of the process for the purpose with lug it therir lingual the teeth. ncisors, and firmly retained the anterior part of the When the incisors were moved as far forward as prac-
icable (Fig. 11, which shows the case af ter six months),

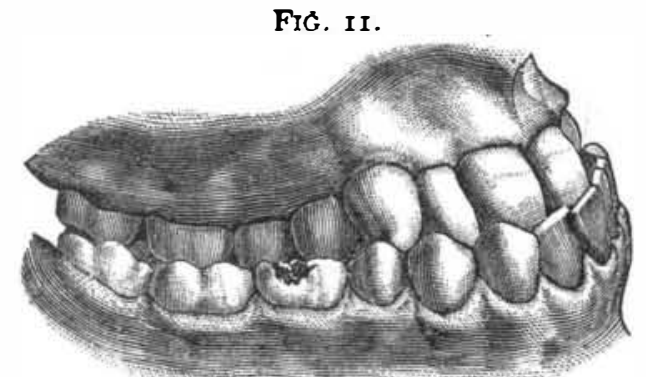

This metal appliance was made of brass to cover the Fig 13.

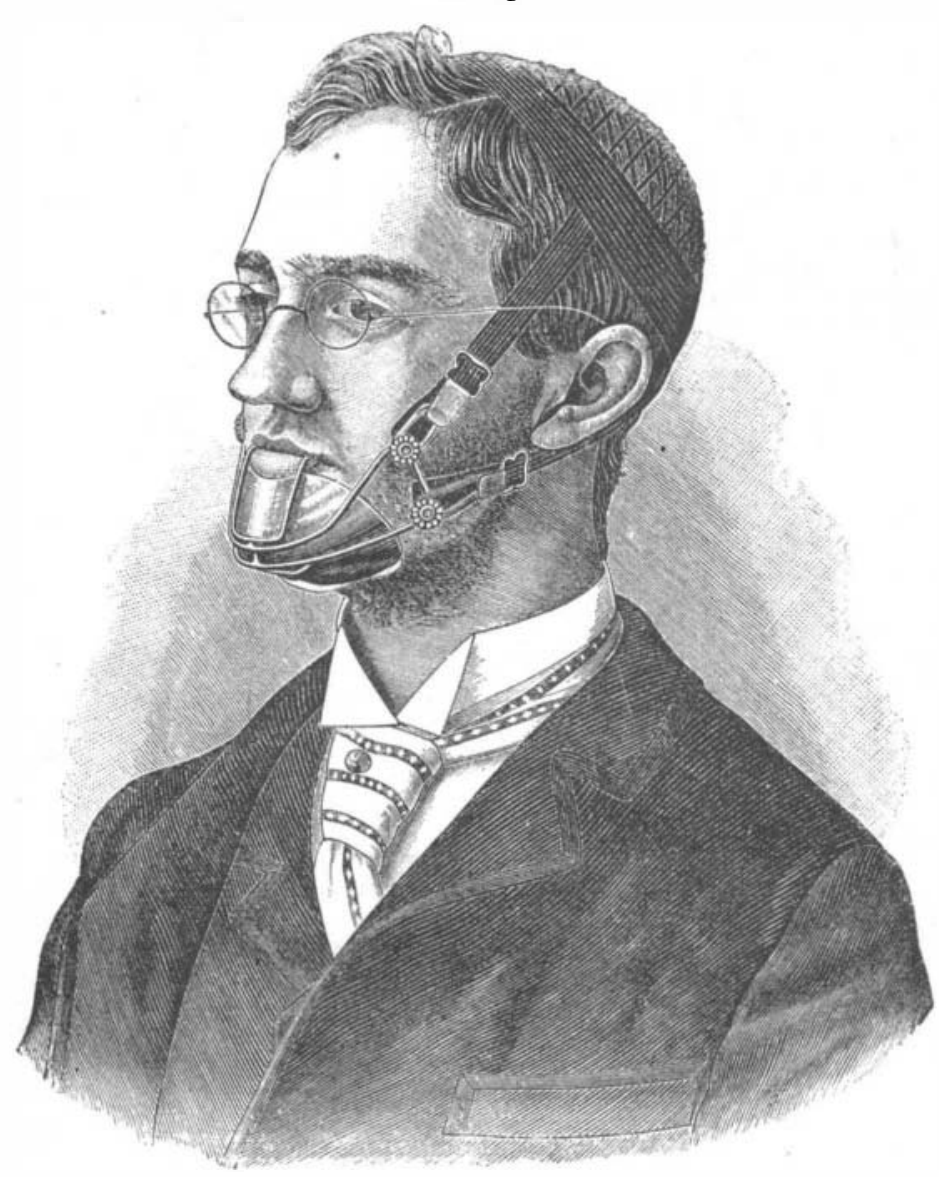

taining a plate, or collars with slight ridges on their chin. and provided with two perpendicular tubes surfaces can be used as previously described. I now present models and apparatus illustrating a position with the corners of the mouth. A crib was procedure that proved efficient in correcting the posi- made of German silver wire, for the lower incisors and
tion of the teeth in both the upper and lower maxilla
bicuspids. with the main wire on thelabial surface and for a patient twenty-two years of age. The distance extending back, following the outline of the gum, to from the lingual surface of the right superior lateral to 
act as springs on the lingual surface of the incisors. $\mid \begin{aligned} & \text { will speak for itself, but its first speech will be in a solue- } \\ & \text { she }\end{aligned}$ over the erindiog dow pids on either side. The inferior first molars were at until it has become established in the country. But the outset pulpless, and were subsequently extracted. then-well, we will wait and see what then; for the Wire posts were soldered to the main wire, and curved in suitable form to allow room for the action of the
lower lip and to enter the tubes in the chin appliance lower lip and to enter the tubes in the chin appliance
at the proper angle. Two German silver wires were pivoted to the lower part of the chin apparatus, with far and diverging until they were about one and oneFIG. 12.

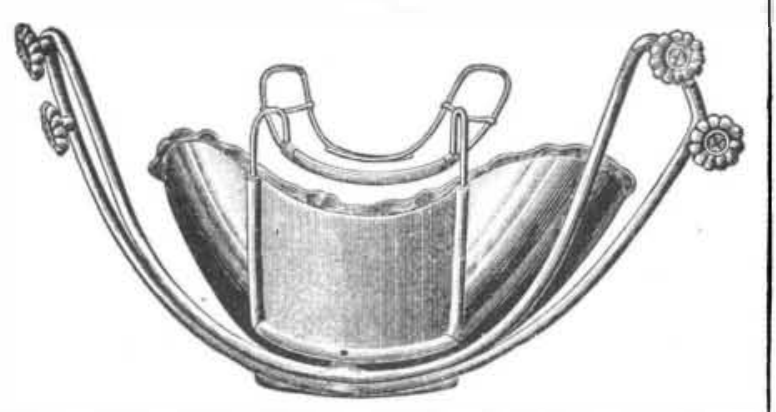

half inches apart. The ends were then bent at sharp angles and united with solder. A metal button was rubber bands, to exert the traction on the appliance.
It is obvious that properly directed traction on the It is obvious that properly directed traction on the
chin piece would force the crib backward carrying all the inclosed lower incisors, cuspids, and bicuspids totherd thed lower incisors, chich were finally aluost touched by the bicuspids,

It will be noticed that the arch of the inferior oral teeth was maintained by the crib while in transit, and that the wolars were in nowise disturbed. There is great advantage in having the wire portion pivoted to the appliance, as it acts like a whiffetree, and thus the appliance is not drawn side ways at each change of the
tension. The part passing over the head was made of tension. The part passing over the head was made of
strong cord network, with a border of silk ribbon about one inch wide, to which were attached two nonelastic suspenders with buckles on either side. The buckles were provided with wire hooks, which were band

The resulting ind provement in the relations of the reath is shown in Fig. 14. the impression for which it-

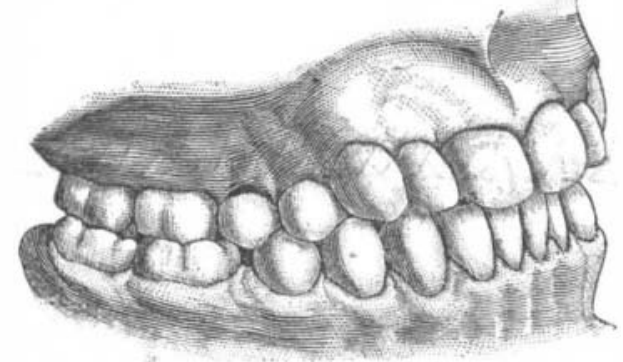

lustration was taken six months after the application of
Cosmos.

NEW VELVET PILE CRISAN'THEMUM.

IT was our privilege last year to present the first authentic figure of the novelty of the season, Mr tune, the figure subjoined being a lifelike represent:

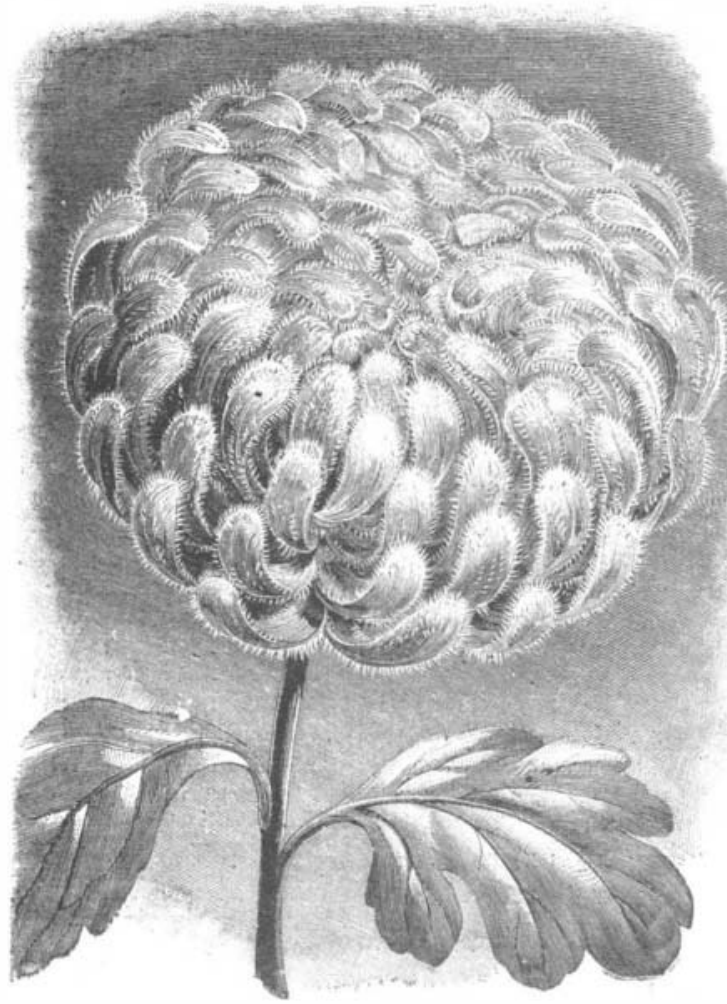

NEW VELVET PILE CHRYSANTHEMUM LOUIS BOEHMER. Color silvery pink, under sides of florets clothed with
silvery hairs.

tion of a typical flower. It is a matter of much interest that this, like its predecessor of the vel vet pile chaPeter Hanterson \& Co., of New York, who made it winning thereby golden honors. Very shortly the flower present here is the portrait of the candidate, an
season at least it, will be at the head of the poll.

TRIYYCLE COACHES. THE coming introduction of tricycle coaches on the
streets has met with the hearty approval of a long

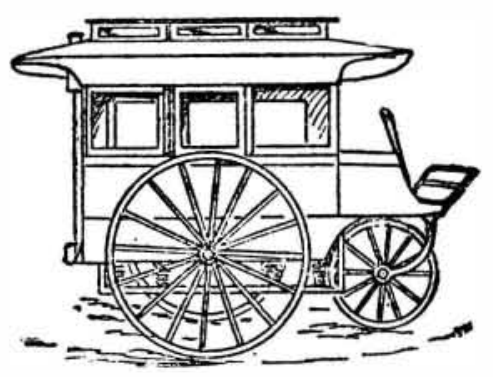

suffering public. whose hopes are now raised that the con som have been running a sauple of the new coaches for several weeks, with a view to testing its adaptation to here, however, wili be twice the size of that, carrying troit Fret. Press.s.

a New Cataloguld of Valanble Paners Contained in ScIENTIFIC AMERICAN SUPPLKMLNT during the past ten years, sent free of eliarg to at
address. MUNN \& $C(0 ., 361$ Broatway, New York.

\section{THE SCIENTIFIC AMERICAN} Architects and Builders Edition.

\section{$\$ 2.50$ a Year. Single Copies, 25 cts.}

This is a Special Edition of the ScIRNTIFIC AMKRIEach number contains abont forty large quarto piges, elyual to about two hondred ordinary book pares. forming, practically, a large and splendid Magazine in colors and with fine engravings. illustrating the most int eresting examples of 1
Construction and allied subjects.

Construction and allied subjects.
A special feature is the presentation in each number A special feature is the presentation in each number
of a variet $y$ of the latest and best plans for private moderate cost as well as the more expensive. Draw ings in perspective and in color are given, together and sherts of Derails.

No other building paper contains so many plans. etails, a:nd specifications regularly presented as the SCIENTILIC AMLRICAN. Hundreds of dwellings have already been erected on the various plans we have
issued during the past year. and wany otbers are in
process of coustruction.

Architects, Builders, and (owners will find this work valuable in furnishing fresh ind useful suggestions All who contemplate building or improving homes. erecting structures of any kind, have before them in
this work an almost endiess series of the latest cn id best tammples from which to wake selections, thus savius
time and money. Mand other subjects, including Sewerage, Pipiug,
Lighting. Warming, Ventilating. Decorating, Laying out of Grounds. etc., are illustrated. An exterisive Compendium of Manufacturers' Announcements is also riven, in which the Inost reliable and approved Build-
ing Materials, Goods. Machines. T'ools, and Appliances
are described and illustrated. with addresses of the wakers, etc.

The fulness, richness, cheapuess, and convenience of
this work have won for it the Largest Circulation of anv Architectural publication in the world

A Catalogue of valuable books on Architecture, Building, Carpentry, Masonry, Heating, Wariuing, pertaining to the at $t$ of $B$

charge. sent to any address.
MUN $\&$ Co., Publishers, 361 Broadway, New York.

Building Plans and Specifications.

In connection with the publication of the Burlping \& Co. furnish plans and specifications for build ings
of every kind. includin? Churches. Schools. Stores, Dwellings, Carriage Houses. Barns. etc.
In this work thes are assisted by able and experinced architects. Full plans, details. and specifications for the various buildings illustrated in this paper Those who contemplate building, or who wish to
The supplied. alter. improve, extend. or add to existing buildings, We invited to coununicate with the undersigned. Our work extends to all parts of the country. Estimates. plans. and draw
moderate. Address

MUNN \& OO.. 361 BROANWAT. NKW YORK. Liphting, Ventilation, and all branches of industry
T I $\mathbf{E}$

\section{Scientific American Supplement.} PUBLISHED WEEKLY.

Terms of Subscription, $\$ 5$ a year.

Sent by wail, postage prepaid, to subscribers in any part of the United States or Canada. Six dollars a ear, sent, prepaid, to any foreign country.

All the back numbers of THE SUPPLEMENT, from the commencement, January 1, 1876, can be had. Price, 10 cents each.

All the back volumes of 'ThF SuPPLeMent can likewise be supplied. Two volumes are issued yearly. Price of each volume, $\$ 2.50$ stitched in paper, or $\$ 3.50$ bound in stiff covers.

COMBINED Rates. - One copy of ScIEnTIFIC AMERICAN and one copy of ScIENTIFIC AMRrican SUPPLEMENT, one year, postpaid, $\$ 7.00$.

A liberal discount to booksellers, news agents, and canvasers

MUNN \& CO., Publishers,

361 Broadway, New York, No y.

TABLE OF CONTFNTS.

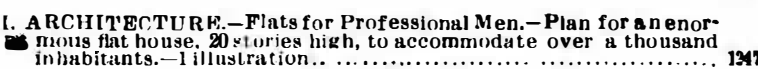

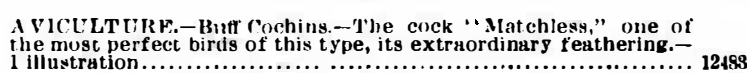

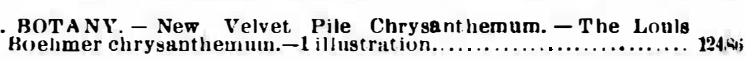

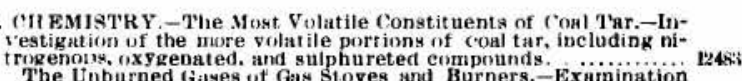

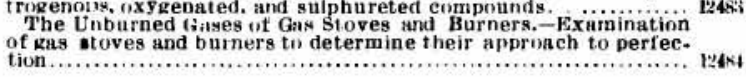

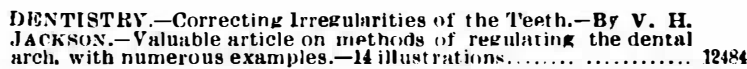

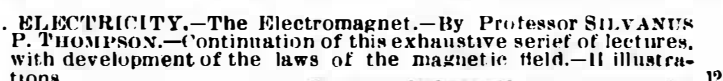

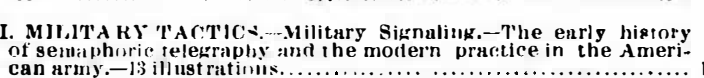

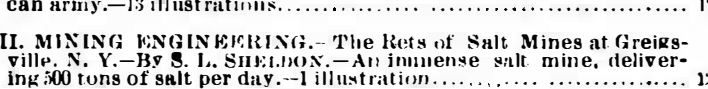

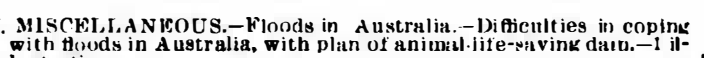

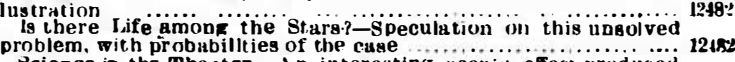

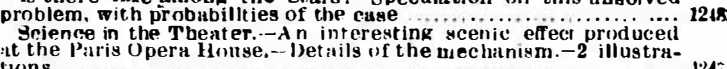

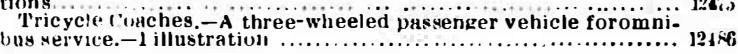

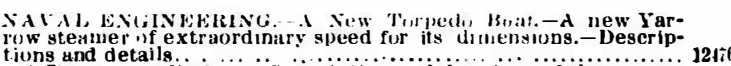

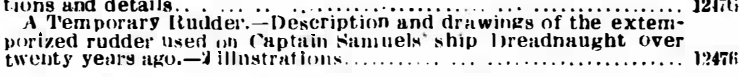

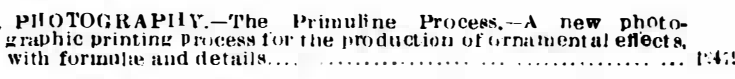

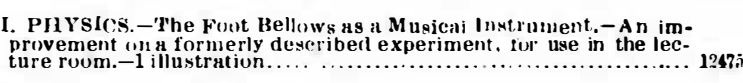

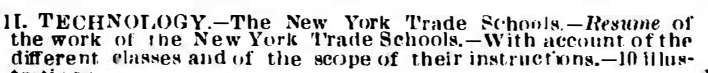

\section{Useful Engineering Books}

\section{Manufacturers, Agriculturists, Chemists, Engineers,} Mechanics, Builders, wen of leisure, and professional
wen, of all classes, need good books in the lime of their iwen, of all classes, need good books in the line of their respective callings. Our post office department permit -mall cost. A comprehensive catalogue of useful book by different authors, on wore than tifty different subects. has recently been published, for free cilinlation. at the office of this paper. Subjects classitied with names of author. Persons desiring a copy have only to ask for it. and it will be mailed to them Address,
MUNN \& CO., 361 Broallway, New York.

\section{PATENTS.}

in connection with the Scientific American, Messrb. MunN \& Co. are solicitors of American and Foreign Patents. have had 42 years' experience, and now have the largest establishment in the world. Patents are obtained on the best terms.

A special notice is made in the Scientific American of all inventions patented through this Agency.
with the name and residence of the Patentee. By the immense circulation thus given. public attention is directed to the iverits of the new patent, and sales or introduction of ten easily effected.

Any person who has made a new discovery or invention can ascertain, free of charge, whether a patent can probably be obtained, by writing to MUNN \& Co. We also send free our Hand Book about the Paten Laws, Patents, Caveats, Trade Marks, their costs and how procured. Address

MUUINI de OO. 361 Isroadway, New York. Branch Uffice. bi:g and bi:s \& st.. Washiugton. D. C. 